Supporting Information for the Manuscript

"Plasma-Assisted Synthesis and Properties of $\mathrm{Na}_{3} \mathrm{~N}$ "

by G. V. Vajenine

\title{
Synthesis
}

Due to air and moisture sensitivity of the reactants and products, all handling was carried out under the atmosphere of purified argon on a vacuum line using the Schlenk technique or in an Ar-filled glove box. Na ( $>99 \%$, Merck) and K ( $>98 \%$, Merck) were purified by sublimation. $\mathrm{N}_{2}(99.998 \%$, Westfalen) was additionally purified by passing through columns with silica gel, molecular sieves, and an $\mathrm{Cr}^{2+}$-based oxysorb catalyst. Electrical discharge was generated capacitively by an HF generator (Hüttinger, $13.56 \mathrm{MHZ}, 1 \mathrm{~kW}$ ) coupled to the reactor through a matchbox.

\section{X-ray diffraction analysis}

on single crystals

Single crystals were sealed in $0.3 \mathrm{~mm}$ capillaries and measured on an IPDS-I diffractometer (Stoe) using $\mathrm{Ag}-\mathrm{K} \alpha$ radiation at room temperature. For details of the data collection, structure solution and refinement please refer to the attached CIF file (see also Table 1). Refinement of the occupation on the nitrogen site (in addition to refining all three independent thermal displacement parameters) leads to the occupancy factor of $1.024(15)$, while assuming an oxygen atom instead of nitrogen results in an occupation factor of $0.814(12)$.

Table S1. Details of data collection and structure refinement for a single crystal of $\mathrm{Na}_{3} \mathrm{~N}$.

Crystal shape and color

Crystal size (mm)

Radiation, wavelength $(\AA)$

Measurement method, $\theta$ range, ${ }^{\circ}$

Crystal system, space group

$a(\AA), V\left(\AA^{3}\right)$

$h, k, l$ ranges

Measured reflections / unique, $R_{\text {int }}$

unique reflections with $I>2 \sigma(I)$

Absorption correction, $T_{\min } / T_{\max }$

Parameters refined / restraints

Atomic positions: $\quad \mathrm{Na}$

$U_{\mathrm{ij}}\left(\AA^{2}\right)$ :

$\mathrm{N}$

$U_{11}(\mathrm{Na}), U_{22}(\mathrm{Na})$ $U_{11}(\mathrm{~N})$

$R 1, w R 2$ for all data

$R 1, w R 2(I>2 \sigma(I))$

Goodness of fit

Largest peak / hole, $\left(\mathrm{e} / \AA^{3}\right)$ prism, dark-blue

$0.26 \times 0.24 \times 0.16$

Ag-K $\alpha, 0.56086$

$\varphi$-scan, 4.9-27.9

cubic, $P m 3 m$

4.7250(16), 105.49(6)

$-6 \leq h \leq 7,-7 \leq k, l \leq 7$

$1316 / 77,0.0688$

62

numerical, $0.9691 / 0.9786$

$4 / 0$

$3 d(1 / 2,0,0)$

$1 a(0,0,0)$

$0.0180(6), 0.0611(7)$

$0.0213(6)$

$0.0451,0.0886$

$0.0378,0.0837$

1.205

$0.275,-0.124$ 
on powder samples

Powder samples were sealed in $0.3 \mathrm{~mm}$ capillaries for data collection on a STADI-P diffractometer (Stoe) using $\mathrm{Cu}-\mathrm{K} \alpha 1$ radiation at room temperature. Structure refinement was carried out using the package GSAS (Larson, A. C.; Von Dreele, R. B. General Structure Analysis System (GSAS), Los Alamos National Laboratory Report LAUR 86748, 2000) and the EXPGUI interface (Toby, B. H. J. Appl. Cryst. 2001, 34, 210-213). Details are given in below for a $\mathrm{Na}_{3} \mathrm{~N}$ sample obtained by nitridation of a $\mathrm{Na}-\mathrm{K}$ alloy followed by removing the excess alloy in a centrifuge, controlled oxidation of the remaining alloy, and manual cleaning of the product (Figure 2 of the main text):

Table S2. Details of Rietveld refinement for $\mathrm{Na}_{3} \mathrm{~N}$.

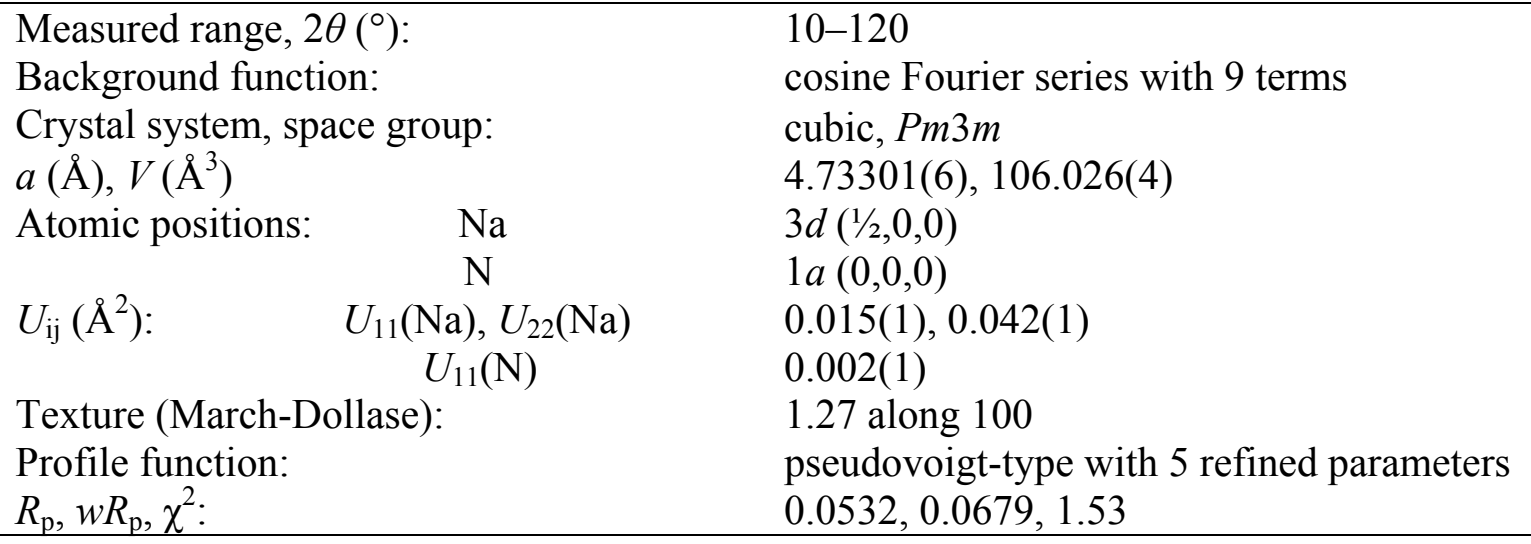

Table S3. Comparison of the lattice parameters obtained for different samples of $\mathrm{Na}_{3} \mathrm{~N}$.

\begin{tabular}{llll}
\hline Sample history & Sample form & $a(\AA)$ & Reference \\
\hline $\begin{array}{l}\mathrm{Na}-\mathrm{K}+\mathrm{N}_{2}, \\
\text { surface oxidized and cleaned } \\
\mathrm{Na}-\mathrm{K}+\mathrm{N}_{2}\end{array}$ & powder & $4.73301(6)$ & this work \\
washed with alloy & powder & $4.73300(4)$ & this work \\
$\mathrm{Na}+\mathrm{N}_{2}$ & powder & $4.73212(10)$ & this work \\
$\mathrm{Na}+\mathrm{N}$ & powder & $4.7325(2)$ & $4 \mathrm{a}$ (main text) \\
& & & \\
$\mathrm{Na}-\mathrm{K}+\mathrm{N}_{2}$ & single crystal & $4.7250(16)$ & this work \\
$\mathrm{Na}-\mathrm{K}+\mathrm{N}_{2}$ & single crystal & $4.7242(17)$ & this work \\
$\mathrm{Na}+\mathrm{N}_{2}$ & single crystal & $4.732(2)$ & this work \\
\hline
\end{tabular}




\section{DTA analysis}

All thermal analysis investigations were performed on samples in laser-welded tantalum ampoules (diameter $2 \mathrm{~mm}$, length $c a .15 \mathrm{~mm}$ ) in an argon atmosphere. Temperature was recorded with a sensitive micro-voltmeter (Hewlett Packard 3457A) and Pt-PtRh thermocouple (Figure S1). The temperature calibration was performed and checked by measuring the extrapolated onset temperatures of the last phase transition $\left(125^{\circ} \mathrm{C}\right)$ and melting $\left(170^{\circ} \mathrm{C}\right)$ peaks of $\mathrm{NH}_{4} \mathrm{NO}_{3}$. The samples were heated from room temperature up to $200^{\circ} \mathrm{C}$ at a rate of $3^{\circ} \mathrm{C} / \mathrm{min}$ and cooled at $1{ }^{\circ} \mathrm{C} / \mathrm{min}$.

An estimate of the decomposition enthalpy of $\mathrm{Na}_{3} \mathrm{~N}$ was made by comparing the integrated areas under the peaks in the $T(\tau)$ curves for the sample $(5.4 \mathrm{mg})$ and the reference material $(10.7 \mathrm{mg})$. For that purpose, the literature value of the enthalpy of the last phase transition (57(1) $\mathrm{J} / \mathrm{g}$ ) for $\mathrm{NH}_{4} \mathrm{NO}_{3}$ was used (Dellien, I. Thermochim. Acta 1982, 55, 181-191). As a result, a value of $+64(2) \mathrm{kJ} / \mathrm{mol}$ was obtained for the decomposition of $\mathrm{Na}_{3} \mathrm{~N}$. In addition, melting and recrystallization of metallic sodium was observed in the DTA data. Assuming complete decomposition of $\mathrm{Na}_{3} \mathrm{~N}$ to $\mathrm{Na}$ and $\mathrm{N}_{2}$, a value of 2.6(1) $\mathrm{kJ} / \mathrm{mol}$ was obtained for the enthalpy of fusion for sodium, which agrees well with the literature value of $2.60 \mathrm{~kJ} / \mathrm{mol}$ (Lide, D. R. (ed.) Chemical Rubber Company handbook of chemistry and physics, CRC Press: Boca Raton, $79^{\text {th }}$ ed., 1998). 


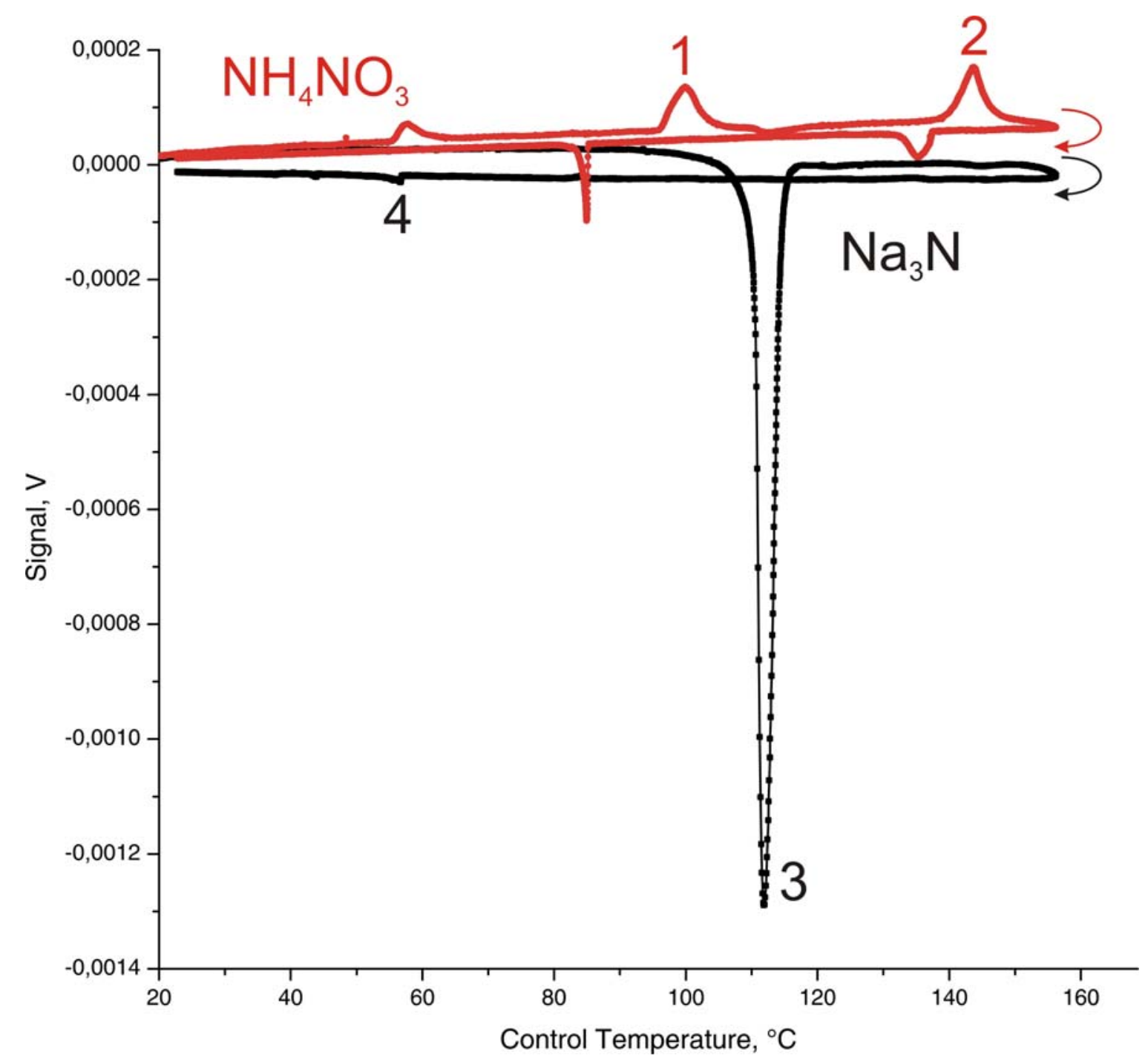

Figure S1. DTA signals of the ampoules with $\mathrm{NH}_{4} \mathrm{NO}_{3}$ (red) and $\mathrm{Na}_{3} \mathrm{~N}$ (black) relative to an empty Ta ampoule during heating followed by cooling (the curve direction is indicated by arrows). Due to the setup design the control temperature is ca. $30^{\circ} \mathrm{C}$ lower than the sample temperature by heating and ca $40^{\circ} \mathrm{C}$ lower by cooling. Reference peaks such as the last phase transition of $\mathrm{NH}_{4} \mathrm{NO}_{3}$ at $125^{\circ} \mathrm{C}$ (1) and melting at $170^{\circ} \mathrm{C}$ (2) were used for accurate calibration. The strong exothermal peak for the $\mathrm{Na}_{3} \mathrm{~N}$ sample during heating ( 3 , corrected temperature of $\sim 140^{\circ} \mathrm{C}$ ) corresponds to irreversible decomposition of $\mathrm{Na}_{3} \mathrm{~N}$, exothermal crystallization of resulting sodium by cooling (4) produced a much weaker effect. By heating this sample again (not shown here) the corresponding endothermal melting peak is observed as well. In this graphical representation the area of the peaks by cooling appears smaller due to lower cooling rate $\left(1^{\circ} \mathrm{C} / \mathrm{min}\right)$ compared to heating $\left(3^{\circ} \mathrm{C} / \mathrm{min}\right)$. 


\section{Additional chemical analysis}

Chemical analysis of a sample of $\mathrm{Na}_{3} \mathrm{~N}$ contaminated by a small amount of $\mathrm{Na}-\mathrm{K}$ alloy yielded the elemental composition given in Table S4. Oxygen contamination, difficult to avoid while handling such sensitive samples, is minimal. Excess sodium compared to that expected based on the $\mathrm{Na}_{3} \mathrm{~N}$ stoichiometry amounts to $4.68 \mathrm{wt} \%$, which together with the potassium corresponds to the alloy of approximately $\mathrm{Na}_{0.5} \mathrm{~K}_{0.5}$ composition. Presence of such alloy, liquid at room temperature, was confirmed by low-temperature powder X-ray diffraction measurements, which showed crystallization of $\mathrm{Na}_{2} \mathrm{~K}$ and elemental potassium upon cooling, as expected based on the binary phase diagram.

Table S4. Results of elemental analysis for a sample of $\mathrm{Na}_{3} \mathrm{~N}$ obtained from $\mathrm{Na}-\mathrm{K}$ alloy.

\begin{tabular}{ccccc}
\hline Element & $\mathrm{N}$ & $\mathrm{O}$ & $\mathrm{Na}$ & $\mathrm{K}$ \\
\hline wt.\% (two analyses) & $14.8,14.8$ & $0.31,0.38$ & $78.0,77.1$ & $8.20,7,54$ \\
average & 14.8 & 0.345 & 77.55 & 7.87 \\
\hline
\end{tabular}

